\title{
Turbulence and diapycnal mixing over the East Pacific Rise crest near $10^{\circ} \mathrm{N}$
}

\author{
A. M. Thurnherr ${ }^{1}$ and L. C. St. Laurent ${ }^{2}$ \\ Received 19 May 2011; revised 1 July 2011; accepted 1 July 2011; published 13 August 2011.
}

[1] Turbulent mixing plays an important role in the return path of the global overturning circulation of the ocean. Previous measurements indicate that much of the mixing takes place near topography, in particular near seamounts and mid-ocean ridges. Here we report on the first microstructure data set collected over the crest and flanks of a fast-spreading ridge. The data indicate that in spite of weak tidally modulated background turbulence levels $\left(\epsilon \approx 10^{-10} \mathrm{~W} \mathrm{~kg}^{-1}\right)$ diapycnal diffusivity is elevated above $10^{-4} \mathrm{~m}^{2} \mathrm{~s}^{-1}$ below crest depth of the ridge throughout the entire region because of the weak density stratification. Near the peaks and in the narrow deep passages of a chain of seamounts, where large horizontal velocities have been observed, turbulence levels are elevated by up to an order of magnitude above background. We conclude that topographic organization plays an important role in determining spatial patterns of turbulence in this region and that both tidal and subinertial energy contribute to the mixing. Citation: Thurnherr, A. M., and L. C. St. Laurent (2011), Turbulence and diapycnal mixing over the East Pacific Rise crest near $10^{\circ}$ N, Geophys. Res. Lett., 38, L15613, doi:10.1029/2011GL048207.

\section{Introduction}

[2] Away from boundaries, diapycnal mixing due to turbulence is the primary mechanism changing the density of water in the ocean. As a result, turbulence is intrinsically linked to the global overturning circulation and, therefore, to climate. The limited available measurements of turbulence and mixing in the deep ocean suggest a correlation with "topographic roughness" [Polzin et al., 1997]. In contrast to slow-spreading ridges, such as the MAR, where high levels of turbulence and mixing have been observed, faster-spreading ridges, such as the East Pacific Rise (EPR), are topographically smoother and, therefore, expected to be associated with lower turbulence and mixing levels. Here, we report on the first set of microstructure profiles obtained near the crest of a fast spreading mid-ocean ridge, the EPR between $9^{\circ} 30^{\prime}$ and $10^{\circ} \mathrm{N}$.

\section{Data}

[3] In November 2007, a CTD/LADCP/microstructure survey was carried out in the eastern tropical Pacific near the crest of the EPR between $9^{\circ} 30^{\prime}$ and $10^{\circ} \mathrm{N}$ (Figure 1). The data were collected during the third cruise of the LADDER project

\footnotetext{
${ }^{1}$ Division of Ocean and Climate Physics, Lamont-Doherty Earth Observatory, Palisades, New York, USA.

${ }^{2}$ Department of Physical Oceanography, Woods Hole Oceanographic Institution, Woods Hole, Massachusetts, USA.

Copyright 2011 by the American Geophysical Union. 0094-8276/11/2011GL048207
}

(LArval Dispersal along the Deep East-pacific Rise), in the context of which a 40-day tracer-release experiment had been carried out between November 2006 and January 2007 [Jackson et al., 2010]. The large-scale topography of the eastern tropical Pacific is dominated by the meridionally trending EPR but in the LADDER study region there are seamounts rising hundreds of meters above the ridge-crest depth of $\approx 2500-2600 \mathrm{~m}$. Particularly prominent are the peaks of the Lamont Seamount Chain, which rise from the western EPR flank near $10^{\circ} \mathrm{N}$ to summit depths between 1700 and $1900 \mathrm{~m}$ and strongly affect the regional circulation [Thurnherr et al., 2011]. Along the crest of the EPR there are numerous hydrothermal sources, which is one of the primary reasons why this region has been designated as one of the three integrated study sites of the RIDGE2000 program.

[4] The survey was carried out with two different instrument platforms collecting simultaneous full-depth profiles. At each of the 37 stations occupied with both instruments the following operations were carried out: 1) an untethered Rockland Scientific VMP-6000 microstructure profiler was deployed, 2) a standard CTD/LADCP profile was collected less than $300 \mathrm{~m}$ from the deployment location of the microstructure profiler, and 3) the microstructure profiler, which typically surfaced within a few hundred meters of the vessel 5 to 10 minutes after the CTD/LADCP package had been brought on deck, was recovered. The data from the CTD/ LADCP system were processed using standard methods for details, see Thurnherr et al. [2011]. Estimates of the turbulent dissipation rate of kinetic energy $(\epsilon)$ were derived from the VMP-6000 measurements through spectral analysis of the velocity microstructure.

\section{Turbulence}

[5] The regional distribution of microstructure-derived kinetic-energy dissipation in the bottom $500 \mathrm{~m}$ of the water column is characterized by a clear correlation between proximity to seamounts and turbulence levels (Figure 1). While most of the profiles from the EPR-crest (blue) and -flanks (green) are associated with near-bottom dissipations of $\approx 10^{-10} \mathrm{~W} \mathrm{~kg}^{-1}$, the near-bottom turbulence levels over the seamount crests (red) and in the saddles between the seamounts of the Lamont Chain (magenta) are up to an order of magnitude larger. Individual dissipation profiles show that, away from an energetic nearsurface layer, enhanced turbulence occurs in patches associated with vertical scales up to $\approx 100 \mathrm{~m}$ (Figure 2 , left). Over the EPR crest and flanks, the peak dissipation values in these turbulent patches do not exceed $5 \times 10^{-9} \mathrm{~W} \mathrm{~kg}^{-1}$. The single exception is a profile from the ridge crest at $9^{\circ} 45^{\prime} \mathrm{N}$, which is associated with mean dissipations in the bottom $500 \mathrm{~m}$ of the water column exceeding $4 \times 10^{-10} \mathrm{~W} \mathrm{~kg}^{-1}$ (Figure 1). Inspection of the corresponding profiles from the microstruc- 


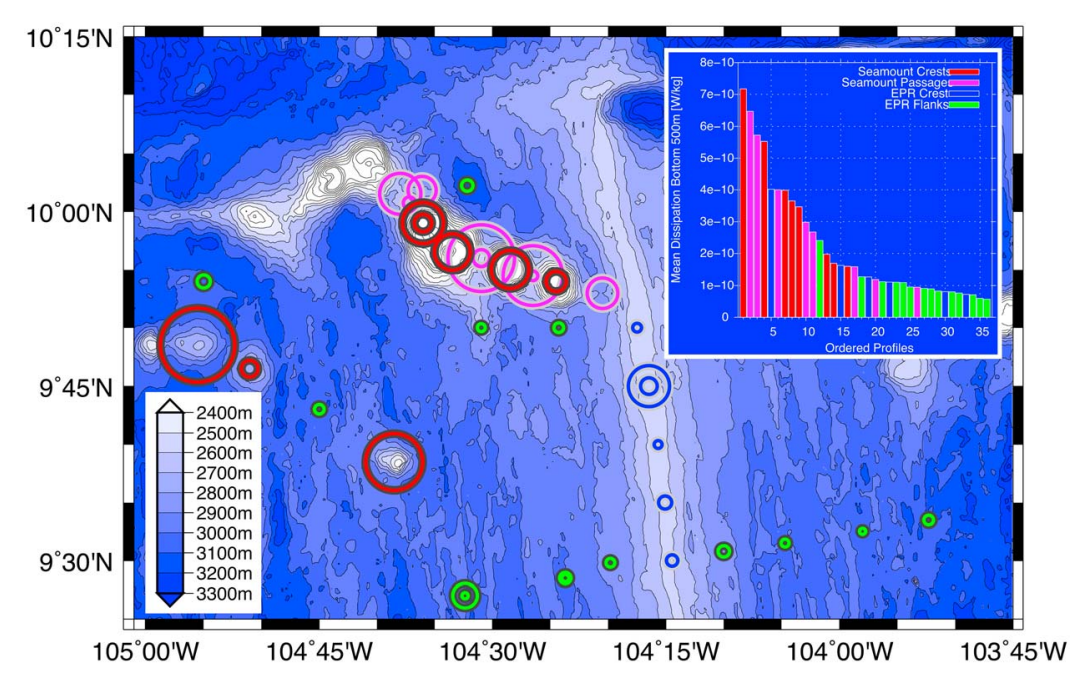

Figure 1. Topography of the LADDER study region and mean kinetic-energy dissipation in the bottom $500 \mathrm{~m}$ of each microstructure profile (circles). Inset: Distribution of near-bottom dissipation. The dissipation circles (main panel) and bars (inset) are color-coded according to the local topographic setting, as indicated in the legend of the inset.

ture profiler and from the CTD indicates a patch of strong mixing with peak dissipations exceeding $1.5 \times 10^{-8} \mathrm{~W} \mathrm{~kg}^{-1}$ associated with a buoyant hydrothermal plume (not shown). The observed dissipation in the bottom $500 \mathrm{~m}$ over the EPR flanks co-varies with the spring-neap modulation of the semidiurnal tide (Figure 2, right), which was determined from a tidal analysis of a current-meter record collected in the same region [Thurnherr et al., 2011]. While a regression analysis reveals that the tidal modulation explains only about $35 \%$ of the observed variance in dissipation, the corresponding $p$-values (see Figure 2 caption) suggest that the correlation is most likely statistically significant.

[6] In contrast to the situation on the EPR crest and flanks, most dissipation profiles taken over seamount crests and in the narrow passages of the Lamont Seamount Chain are characterized by patches of enhanced turbulence associated with peak dissipations $>5 \times 10^{-9} \mathrm{~W} \mathrm{~kg}^{-1}$ (Figure 2, left). Over the seamount crests, the dissipation is often primarily enhanced in a single $\approx 100 \mathrm{~m}$-thick layer near the seabed. The dissipation profiles from the narrow passages between the Lamont seamounts, on the other hand, are typically characterized by closely spaced patches of elevated dissipation extending from the seabed to slightly above the peak depth of the adjacent seamounts $(\approx 1700 \mathrm{~m}$ in case of the two magenta profiles shown in Figure 2).

[7] Ensemble-averaged dissipation profiles further elucidate the relation between topographic setting and turbulence (Figure 3). The turbulence levels over the crest and flanks of the EPR are similar and show little vertical structure the respective mean values and standard deviations below $500 \mathrm{~m}$ are $1.0( \pm 0.3) \times 10^{-10}$ and $1.2( \pm 0.3) \times 10^{-10} \mathrm{~W} \mathrm{~kg}^{-1}$. In contrast, the mean turbulence levels are elevated both
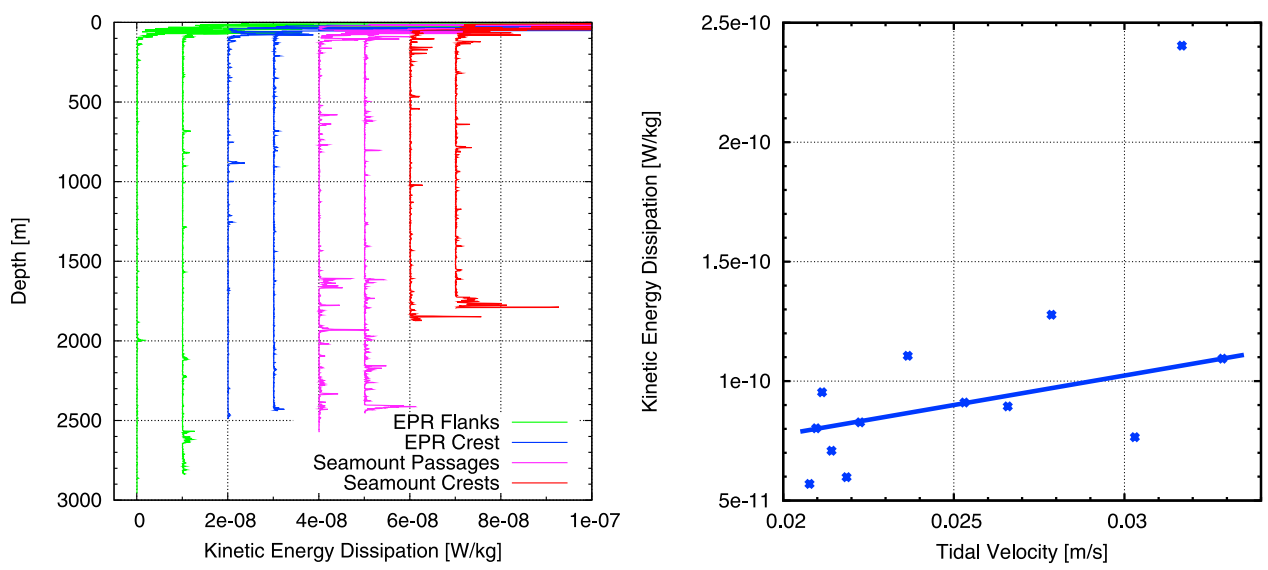

Figure 2. (left) Example profiles of kinetic energy dissipation, color coded as in Figure 1. Vertical resolution of the profiles is $1 \mathrm{~m}$. Subsequent profiles are horizontally offset by $10^{-8} \mathrm{~W} \mathrm{~kg}^{-1}$. (right) Mean kinetic-energy dissipation in the bottom $500 \mathrm{~m}$ of each microstructure profile from the EPR flanks plotted against daily averaged kinetic energy of the semidiurnal tide, derived from a regional current-meter record. A regression analysis yields a $p$-value of 0.03 , suggesting that the correlation is statistically significant, although the $p$-value increases to 0.09 when the analysis is repeated after removing the sample with the highest dissipation. 


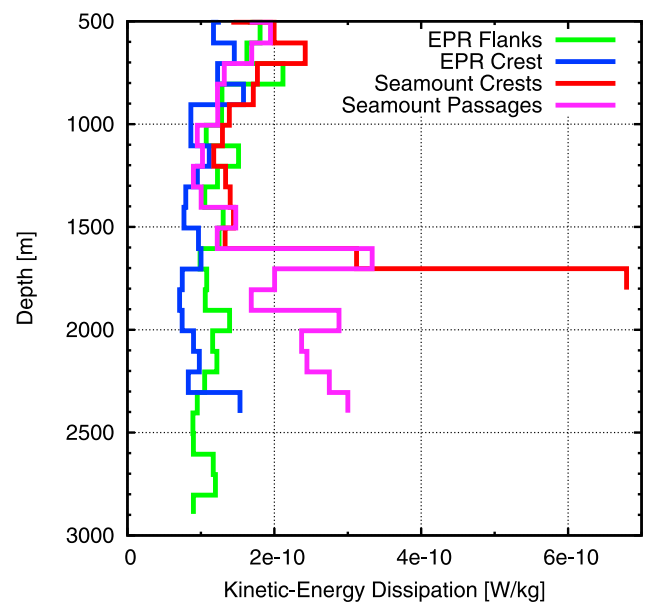

Figure 3. Topographically classified depth-averaged profiles of kinetic energy dissipation. Each bin contains values from at least 5 profiles. The EPR Crest average was calculated without the profile intersecting a buoyant hydrothermal plume (see text for additional information).

over the crests of seamounts and in the narrow passages of the Lamont seamount chain. In both settings, elevated dissipation values are restricted to depths below $1600 \mathrm{~m}$, i.e., the elevated turbulence does not extend very far above the seamount topography. Over the seamount crests the mean turbulence is elevated by nearly an order of magnitude in an $\approx 100 \mathrm{~m}$-thick near-bottom layer. In the passages between the Lamont seamounts, on the other hand, the mean turbulence is characterized by a local maximum near the depth of the seamount crests superimposed on a gradual increase toward the seabed. Consistent with Figure 1 the average dissipation in the bottom $500 \mathrm{~m}$ of the water column over the seamount crests and in the passages of the Lamont chain $\left(3.6 \times 10^{-10}\right.$ and $3.2 \times 10^{-10} \mathrm{~W} \mathrm{~kg}^{-1}$, respectively) are elevated approximately threefold when compared to the corresponding averages from the EPR crest and flanks. Given the intermittency of oceanic turbulence and the small number of profiles these averages were calculated from, the associated uncertainties are rather large - bootstrapping indicates a range of $\approx 2-5 \times 10^{-10} \mathrm{~W} \mathrm{~kg}^{-1}$ at the $95 \%$ confidence limit in both cases.

\section{Mixing}

[8] In order to provide quantitative estimates of mixing, e.g., for comparison with results from the LADDER tracer-release experiment, turbulent eddy diffusivities must be calculated. Here, we use the well known model of Osborn [1980] to relate measurements of dissipation and buoyancy frequency $(N)$ to an eddy diffusivity $\kappa$, i.e., $\kappa=\Gamma \epsilon / N^{2}$, where $\Gamma$ is the mixing efficiency parameter. Here, we use $\Gamma=0.2$, a value found to be applicable in previous examinations of abyssal mixing [e.g., St. Laurent et al. [2001b]. In order to avoid contamination of the mean diffusivity profiles by spikes related to (nearly-) vanishing density stratification, e.g., in active overturns, $N$ is calculated from Thorpe-sorted profiles and $N$ and $\epsilon$ are ensemble averaged separately to yield mean diffusivity profiles (Figure 4). Except for a weak local minimum between 1700 and $1800 \mathrm{~m}$ possibly related to the crests of the seamounts in the Lamont Chain there is no evidence for any significant topographic influence on the mean buoyancy-frequency profiles (Figure 4, left), i.e., the differences between mixing levels in the different topographic classes (Figure 4, right) are dominated by differences in turbulence levels (section 3 ). In contrast, the overall increase of diffusivity with depth apparent in all four mean profiles is dominated by the vertical gradient of density stratification. This is immediately apparent in case of the mean profiles from the EPR crest and flanks, where the dissipation below $500 \mathrm{~m}$ shows no indication for an increase of turbulence with depth (Figure 3). Similar to kinetic energy dissipation (Figure 2, right), the observed eddy diffusivities in the bottom $500 \mathrm{~m}$ over the EPR flanks co-varies with the spring-neap modulation of the semidiurnal tide (not shown).

\section{Discussion}

[9] The microstructure measurements obtained during LADDER-3 reveal a clear connection between turbulence/ mixing and topography near the crest of the EPR between $9^{\circ} 30^{\prime}$ and $10^{\circ} \mathrm{N}$. Away from seamounts the dissipation is spatially quite uniform and associated with values between $0.6 \times 10^{-10}$ and $1.5 \times 10^{-10} \mathrm{~W} \mathrm{~kg}^{-1}$. We interpret this range as
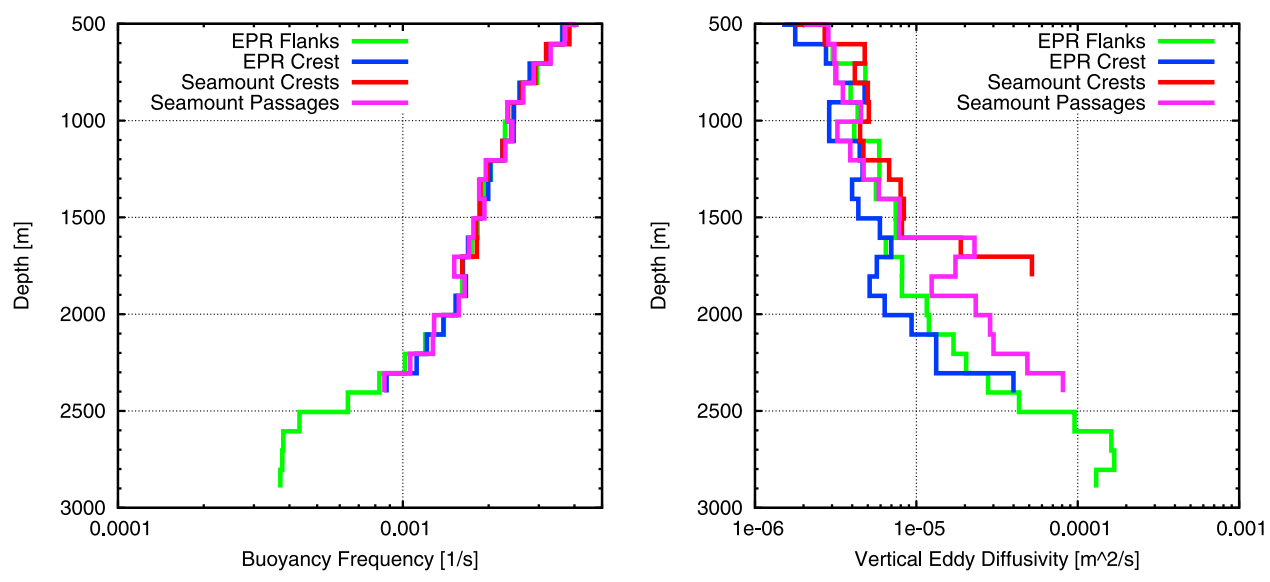

Figure 4. Topographically classified ensemble-averaged profiles. The EPR Crest averages were estimated without the buoyant-plume profile. (left) Buoyancy frequency. (right) Microstructure-derived vertical eddy diffusivity. 
the regional "background level" of turbulence. While measurement noise levels for the VMP-6000 are of similar magnitude $\left(0.5-0.7 \times 10^{-10} \mathrm{~W} \mathrm{~kg}^{-1}\right.$, based on inspection of microscale shear spectra in quiet parts of the profiles), the observed spring-neap modulation precludes the possibility that the measurements of this background turbulence are noise-dominated. Superimposed on this background turbulence, many of the profiles collected directly over seamount crests in this region show $\approx 100 \mathrm{~m}$-thick layers of elevated turbulence with typical dissipation levels nearly an order of magnitude above background. Turbulence in the narrow passages of the Lamont Seamount Chain is elevated all the way between the seabed and the peaks of the seamounts, i.e., over a vertical scale of $\approx 1000 \mathrm{~m}$, although the mean dissipation there is only $2-3 \times$ greater than background. The microstructure profiles were collected between Nov. 15 and Dec. 1, 2007, with a full moon on Nov. 24. Sampling of the seamount stations was approximately evenly distributed throughout the measurement period except for a three-day gap between Nov. 24 and Nov. 28, i.e., during the peak of the spring tide, making it unlikely that the elevated turbulence and mixing observed near the seamounts is an artifact of temporal variability.

[10] The lack of vertical structure in the mean dissipation profiles away from the seamounts indicates that the spatial distribution of the main instability processes feeding the turbulence is fairly homogeneous. We interpret this as evidence that the regional background mixing is caused by breaking internal waves. The observed spring-neap modulation furthermore strongly suggests that this background mixing is tidally driven and, therefore, consistent with the assumptions underlying tidal-mixing parameterizations, such as the one proposed by Jayne and St. Laurent [2001]. Over the seamount crests and in the deep passages of the Lamont Chain, on the other hand, the turbulence levels increase toward the seabed and there is no apparent correlation with the spring-neap cycle. In the passages both tidal and subinertial horizontal velocities on the order of $10 \mathrm{~cm} \mathrm{~s}^{-1}$ have been observed during the microstructure measurement cruise, with instantaneous speeds exceeding $20 \mathrm{~cm} \mathrm{~s}^{-1}$ in some cases [Thurnherr et al., 2011]. The subinertial flows provide an additional source for turbulent kinetic energy in the seamount passages and, therefore, it seems likely that at least some of the mixing near the seamounts is caused by processes that are unrelated to internal waves and, consequently, not accurately represented by tidal-mixing parameterizations. It is interesting to note that the elevated turbulence in the passages between the Lamont seamounts is largely restricted to depths below the peaks of the adjacent seamounts. This is similar to the situation observed on the western flank of the Mid-Atlantic Ridge in the South Atlantic where most of the turbulent diapycnal fluxes take place within the topographic envelope of the fracture-zone canyons [St. Laurent et al., 2001a; Thurnherr et al., 2005]. We therefore conclude that, just like on the Mid-Atlantic Ridge, "topographic organization" has a strong effect on turbulence and mixing near the EPR crest in our study region.

[11] In order to put the LADDER-3 measurements into a wider context they can be compared to the well known microstructure data collected in the context of the WOCE Deep Basin Experiment (DBE) in subtropical Brazil Basin and over the western flank of the MAR [Polzin et al., 1997; St. Laurent et al., 2001b]. While the regional background turbulence near the crest EPR $\left(1.1 \times 10^{-10} \mathrm{~W} \mathrm{~kg}^{-1}\right)$ is slightly more energetic than the mean turbulence levels observed over the topographically smooth abyssal plain in the Brazil Basin $(0.9 \times$ $10^{-10} \mathrm{~W} \mathrm{~kg}^{-1}$; all mean DBE values are taken from Table 1 of Thurnherr et al. [2005]) it is weaker than the mean turbulence observed over the flank of the Mid-Atlantic Ridge in the South Atlantic $\left(1.9 \times 10^{-10} \mathrm{~W} \mathrm{~kg}^{-1}\right)$. Comparing the turbulence levels within the "topographic envelope," the mean dissipation observed in the passages between the Lamont Seamounts $(\approx 2-$ $\left.5 \times 10^{-10} \mathrm{~W} \mathrm{~kg}^{-1}\right)$ is considerably weaker than the corresponding mean turbulence level observed in fracture-zone canyons on the western MAR flank $\left(9.3 \times 10^{-10} \mathrm{~W} \mathrm{~kg}^{-1}\right)$.

[12] In contrast to the turbulence intensity, the spatial distribution of mixing (turbulent eddy diffusivity) in our study region is not dominated by topographic effects but, rather, by the vertical variation of density stratification. Thus the largest mean diffusivities, approaching $2 \times 10^{-4} \mathrm{~m}^{2} \mathrm{~s}^{-1}$, were observed below crest depth over the flanks of the EPR where the turbulence is not elevated. The LADDER tracerrelease experiment carried out in the same region approximately one year before the microstructure survey yielded a mean diffusivity estimate of $\approx 2 \times 10^{-4} \mathrm{~m}^{2} \mathrm{~s}^{-1}$ [Jackson et al., 2010]. Considering the fact that the most of the tracer dispersed between $\approx 2600$ and $2750 \mathrm{~m}$ [Jackson et al., 2010, Figure 7] we conclude, based on our Figure 4, that the tracer- and microstructure-derived mixing estimates are mutually consistent, and that no "seamount mixing" is required to account for the tracer observations.

[13] Acknowledgments. Funding for the LADDER project and the microstructure add-on was provided by the National Science Foundation under grants OCE-0728766, OCE-0425361 and OCE-0424953. In addition to the very capable and helpful officers and crew of the R/V Atlantis II, we are grateful to the LADDER PIs for providing significant ship time during LADDER-3 to collect the microstructure data.

[14] The Editor thanks two anonymous reviewers for their assistance in evaluating this paper.

\section{References}

Jackson, P. R., J. R. Ledwell, and A. M. Thurnherr (2010), Dispersion of a tracer on the East Pacific Rise $\left(9^{\circ}\right.$ to $\left.10^{\circ} \mathrm{N}\right)$, including the influence of hydrothermal plumes, Deep Sea Res., Part I, 57, 37-52.

Jayne, S. R., and L. C. St. Laurent (2001), Parameterizing tidal dissipation over rough topography, Geophys. Res. Lett., 28, 811-814.

Osborn, T. R. (1980), Estimates of the local rate of vertical diffusion from dissipation measurements, J. Phys. Oceanogr., 10, 83-89.

Polzin, K. L., J. M. Toole, J. R. Ledwell, and R. W. Schmitt (1997), Spatial variability of turbulent mixing in the abyssal ocean, Science, 276, 93-96.

St. Laurent, L., J. M. Toole, and R. W. Schmitt (2001a), Mixing and diapycnal advection in the ocean, paper presented at the 'Aha Huliko'a Winter Workshop, Univ. of Hawaii, Honolulu.

St. Laurent, L. C., J. M. Toole, and R. W. Schmitt (2001b), Buoyancy forcing by turbulence above rough topography in the abyssal Brazil Basin, J. Phys. Oceanogr., 31, 3476-3495.

Thurnherr, A. M., L. C. St. Laurent, K. G. Speer, J. M. Toole, and J. R. Ledwell (2005), Mixing associated with sills in a canyon on the midocean ridge flank, J. Phys. Oceanogr., 35, 1370-1381.

Thurnherr, A. M., J. R. Ledwell, J. W. Lavelle, and L. S. Mullineaux (2011), Hydrography and circulation near the crest of the East Pacific Rise between $9^{\circ}$ and $10^{\circ}$ N, Deep Sea Res., Part I, 58, 365-376, doi:10.1016/j. dsr.2011.01.009.

L. C. St. Laurent, Department of Physical Oceanography, Woods Hole Oceanographic Institution, 266 Woods Hole Rd., MS 29, Woods Hole, MA 02543, USA. (1stlaurent@whoi.edu)

A. M. Thurnherr, Division of Ocean and Climate Physics, LamontDoherty Earth Observatory, 61 Rte. 9W, Palisades, NY 10964, USA. (ant@1deo.columbia.edu) 